\begin{tabular}{|l|l|l|l|l|}
\hline Cryst. Res. Technol. & 27 & 1992 & 5 & $727-739$ \\
\hline
\end{tabular}

\author{
I. Dierking, F. Giesselmann, P. Zugenmaier, G. Pelzl, P. Schiller
}

Institut für Physikalische Chemie, Technische Universität Clausthal, Clausthal-Zellerfeld, Germany, and Fachbereich Chemie, Institut für Physikalische Chemie, Martin-Luther Universität HalleWittenberg, Halle (Saale), Germany

\title{
Determination of the Rotational Viscosity and of the Elastic Constant from Measurements of Switching Times and Threshold Voltage on Planar Oriented $S_{\mathrm{c}}$ Phases
}

The Freedericksz transition of planar oriented $S_{\mathrm{c}}$ phases was studied experimentally with an electrooptical method and the theoretically predicted reorientation along the $S_{\mathrm{c}}$ tilt cone confirmed. Measurements of the threshold voltage and the switching times lead to the determination of the rotational viscosity and the elastic constant for five selected compounds with positive dielectric anisotropy.

Der Freedericksz-Übergang planar orientierter $S_{\mathrm{c}}$ Phasen wurde experimentell mit einer elektrooptischen Methode untersucht und die theoretisch vorhergesagte Kegelmantelbewegung bestätigt. Durch Messungen der Schwellspannung und der Schaltzeiten wurden die Rotationsviskosität und die elastische Konstante für fünf ausgesuchte Verbindungen mit positiver dielektrischer Anistropie bestimmt.

\section{Introduction}

Field induced reorientation in $S_{\mathrm{c}}$ phases was first discussed by RAPINI for a number of different geometric configufations. MeIrovich et. al. were able to show by theoretical investigations that in $S_{\mathrm{c}}$ phases discontinous transitions can occur. In 1979 the dielectric reorientation of planar oriented $S_{\mathrm{c}}$ phases with positive dielectric anisotropy was observed (Pelzl, Schubert et al. 1979; Pelzl, Kolbe et al. 1979).

Fig. 1. Orientation of the director $u$ with respect to the smectic layer plane with layer normal $k$ and tilt angle $\theta . \tau$ is a unit vector orientated parallel to the projection of the director on the smectic layer plane and $\boldsymbol{\xi}$, a fixed unit vector lying on the smectic layer plane, defining an azimuthal angle $\varphi$, between $-\pi$ and $+\pi$. (Schematic drawing according to PeLzL et al. 1987

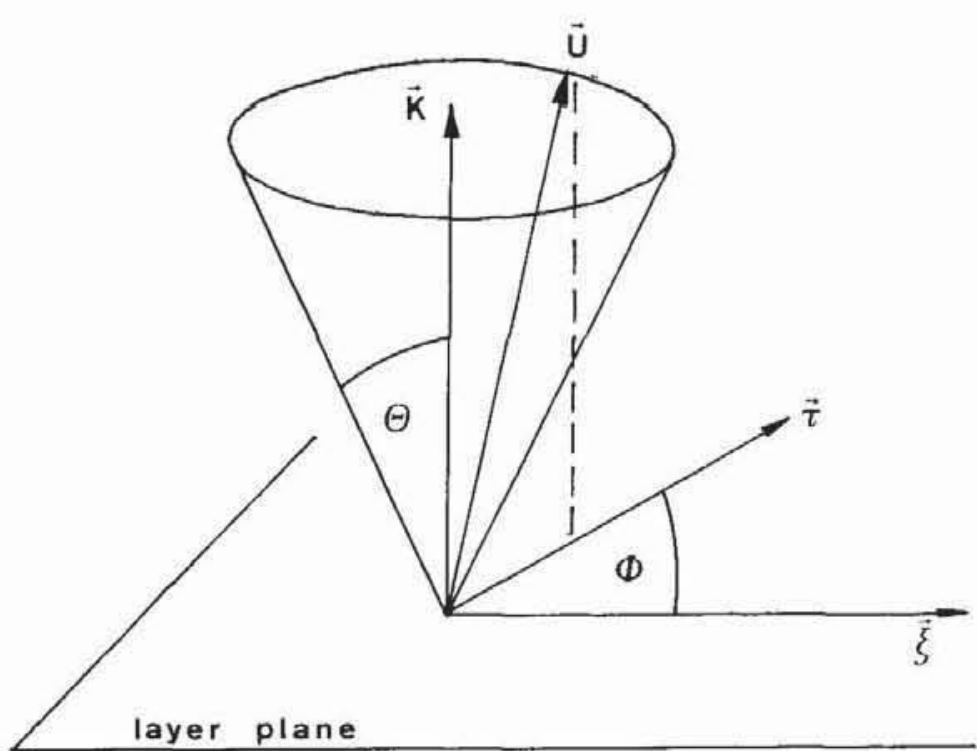




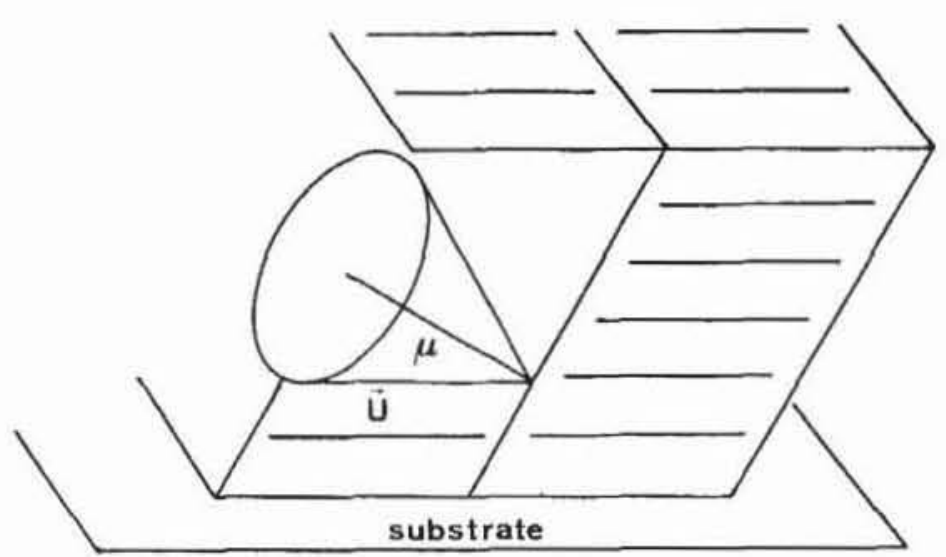

(a)

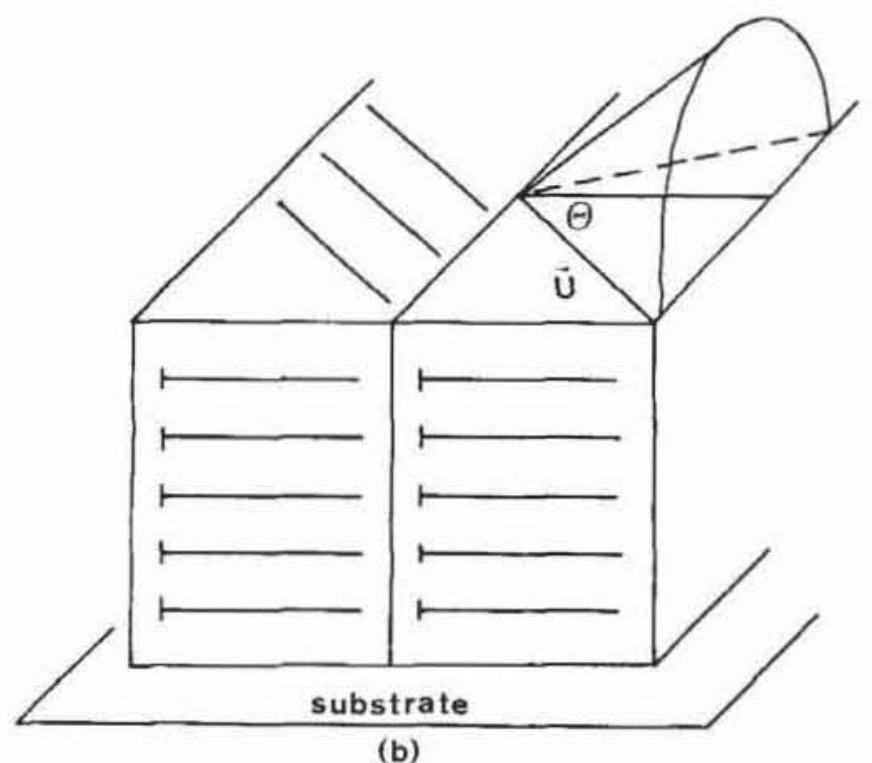

Fig. 2. Borderline cases of planar alignment as explained in the text. (Schematic drawing according to PELzL et al. 1987). Explanation see text

In planar oriented samples, the director $\boldsymbol{u}$ is uniformly aligned parallel to the substrate planes and encloses an angle $\theta$ with the layer normal $\boldsymbol{k}$ (Fig. 1). Application of an electric field in the smectic $C$ phase causes the director to move on a tilt cone with aperture $2 \theta$. Two borderline cases have to be distinguished:

(i) the smectic layer itself forms an angle $\mu$ with respect to the substrate plane (layer tilted geometry, Fig. 2a).

(ii) the smectic layer is perpendicular to the substrate plane with $\mu=0$ (bookshelf geometry, Fig. 2b).

\section{Theoretical}

By geometrical considerations (see Fig. 3) the azimuth angle at the substrate, having layer tilted geometry, is given by

$$
\cos \varphi_{0}=\frac{\tan \mu}{\tan \Theta} .
$$




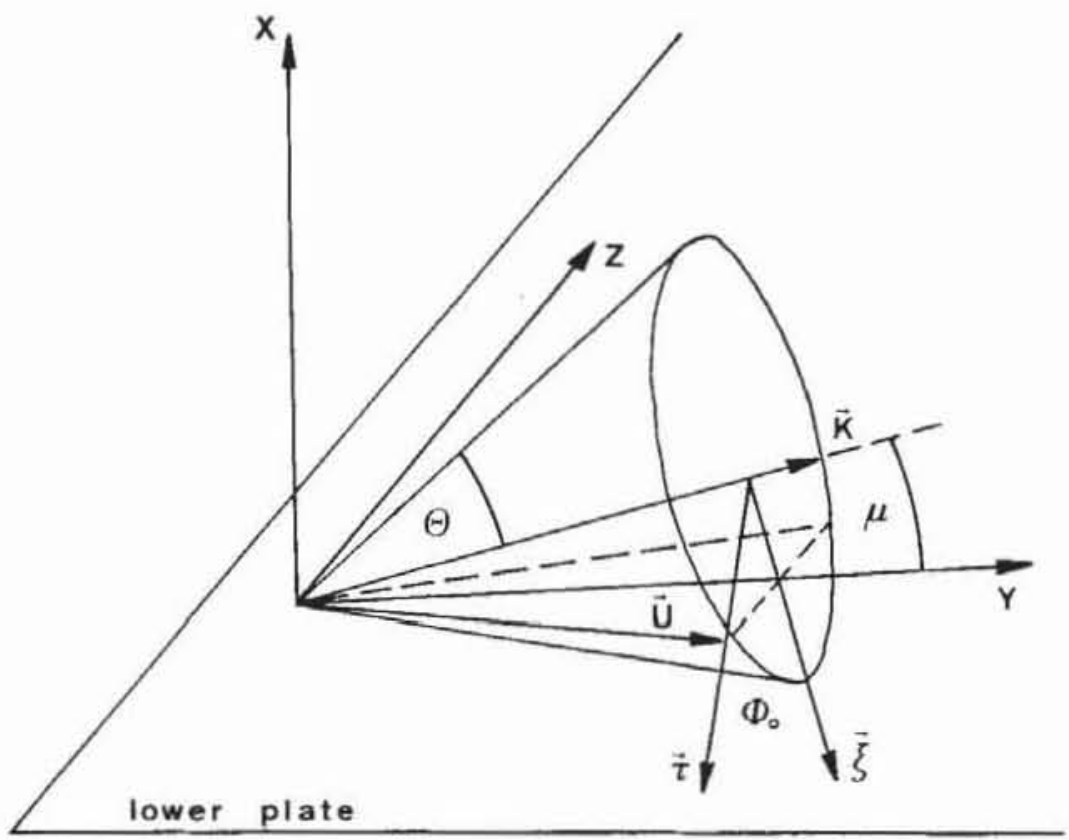

Fig. 3. Planar alignment of the director $u$ at the substrate, $\mu$ being the tilt angle of the layer normal with respect to the substrate, $\Phi_{0}$ the angle between $\tau$ and $\xi$ on the substrate surface $x=0$. (Schematic drawing according to PeLzL et al. 1987)

According to theoretical calculations (PELzL et al. 1987), a threshold-field $E_{\mathrm{c}}$ for the Freedericksz transition is given by

$$
E_{\mathrm{c}}=\frac{C}{D \sin \Theta} \sqrt{\frac{B}{\Delta \varepsilon \varepsilon_{0}}}
$$

with $\pi \leqq C \leqq 4.6 / \cos \theta, D$ the thickness, $B$ the elastic constant, $\Delta \varepsilon>0$ the dielectric anisotropy and $\varepsilon_{0}$ the dielectric field constant.

The constant $C$ for the two borderline cases is

(i) $C=\pi$ for bookshelf geometry with $\mu=0$,

(ii) $C=4.6 / \cos \theta$ for layer-tilted geometry with $\mu=0$.

It is generally accepted that the bookshelf geometry with $\mu=0$ is established after a transition from a nematic to a smectic $\mathrm{C}$ phase (compounds $\mathrm{C} 3$ and $\mathrm{C} 4$ ) and the layer-tilted geometry with $\mu=\theta$ after a transition from a smectic $A$ to a smectic $C$ phase (compounds $C 1, C 2$, and $C 5$ ).

The dynamic behaviour of the relaxation process, that means the decay of a field induced deformation after switching off the electric field, can be described by a diffusion equation (Pelzl et al. 1987) for $\boldsymbol{E}=0$

$$
B \frac{\delta^{2} \varphi^{*}}{\delta x^{2}}-\lambda \frac{\delta \varphi^{*}}{\delta t}=0
$$

with $\varphi^{*}=-\varphi_{0}+\varphi$ and $\lambda$ the rotational viscosity.

The solution of (3)

$$
\varphi^{*}=\varphi^{*}(t=0) \sin \frac{\pi x}{D} e^{-t / \tau}
$$


yields a time constant for the decay of an initial deformation (PelzL et al. 1987)

$$
\tau_{\text {decay }}=\frac{\lambda D^{2}}{B \pi^{2}} .
$$

It should be noted that the decay time is only weakly dependent on the layer tilt angle $\mu$, and equation (5) can be used as a good approximation in all cases.

A simple formula (eq. 6) describing the response to an applied external electric field can only be given for the bookshelf geometry, since the layer tilted geometry invokes a nonlinear differential equation for the description of the dynamic behaviour of the director.

$$
\lambda \frac{\delta \varphi^{*}}{\delta t}=B \frac{d^{2} \varphi^{*}}{\delta x^{2}}-g\left(\varphi^{*}\right)
$$

with

$$
g\left(\varphi^{*}\right)=E^{2} \Delta \varepsilon \varepsilon_{0} \sin ^{2} \Theta \cos \mu\left(\cos \left(\varphi_{0}+\varphi^{*}\right)-\cos \varphi_{0}\right) \sin \left(\varphi_{0}+\varphi^{*}\right)
$$

This differential equation cannot be solved analytically in general.

The solution of eq. (6) for switching on the electric field $E$ above a critical value $\left(E>E_{\mathrm{c}}\right)$ is given by PELzL et al. (1987).

$$
\varphi^{*}=\varphi^{*}(t=0) \sin \frac{\pi x}{D} e^{t / \tau}
$$

with a time constant

$$
\tau_{\text {rise }}=\frac{\lambda}{\Delta \varepsilon \varepsilon_{0} \sin ^{2} \Theta\left(E^{2}-E_{\mathrm{c}}^{2}\right)}
$$

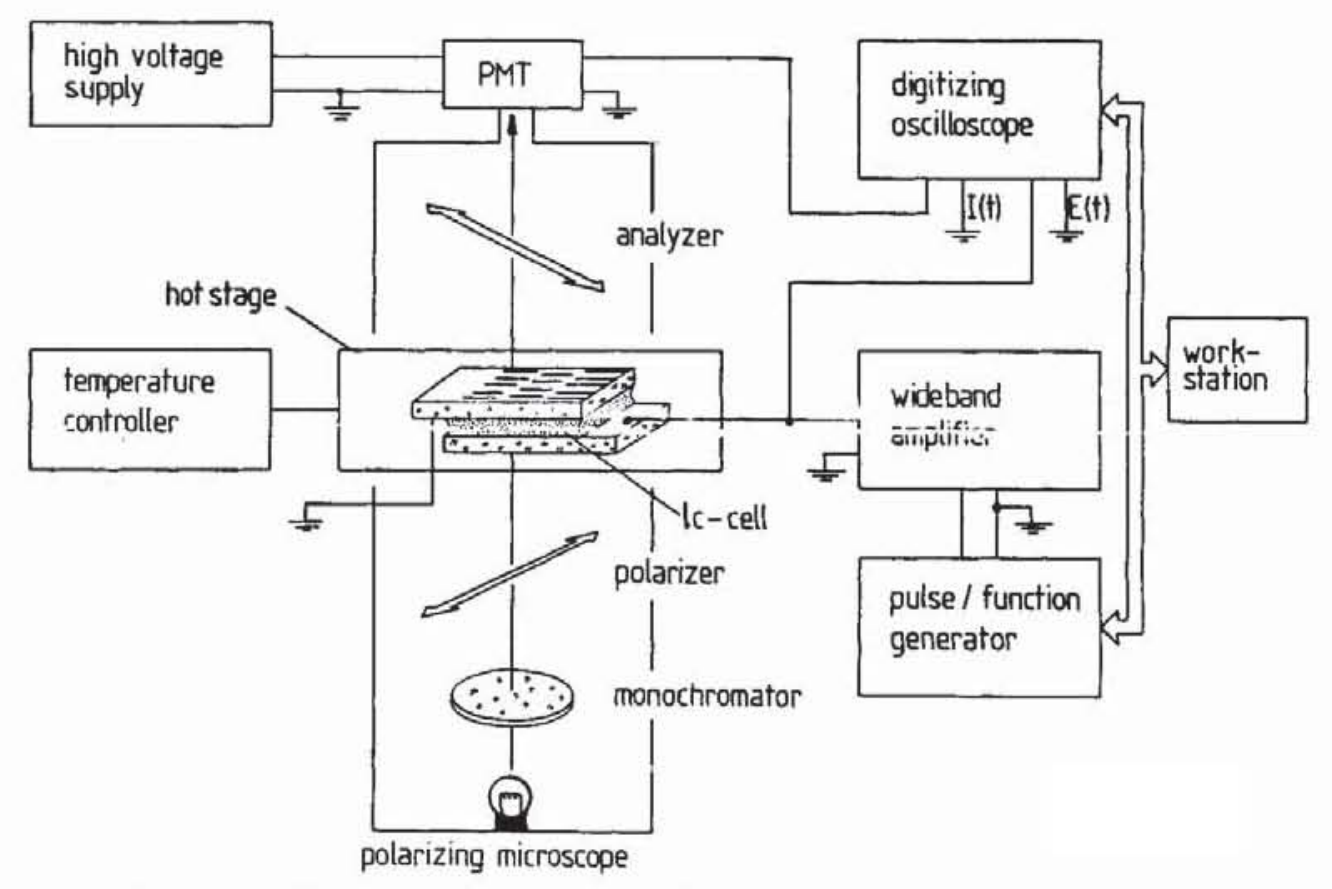

Fig. 4. Schematic diagram of the experimental device. (Schematic drawing according to GIESSELMANN, ZUGENMAIER) 


\section{Experimental}

For the electrooptical studies the liquid crystal materials were sandwiched in commercial $2 \mu \mathrm{m}$ thick cells with electrodes attached and placed in a hot stage under a polarizing microscope. The switching, that is the dielectric reorientation, was induced by a pulse voltage and the changes of the transmission of light observed using a suitable wavelength. The pulse width (usually $5 \mathrm{~ms}$ ) was chosen to asure a complete switching process and to avoid ionic flow through the cell. The pulse repetition rate (mostly $1 \mathrm{cps}$ ) was kept in a range that the reorientation of the molecules into the equilibrium state was completed. The field induced change of light intensity was detected by means of a photomultiplier and transferred to a digital memory oscilloscope. The 64 single measurements were averaged to eliminate the statistical noise. The averaged values were then transferred to a computer-terminal for further analysis.

The treshold voltage of the Freedericksz transition was determined by increasing the field strength on the cell in small steps until first signs of a switching process were detected on the oscilloscope.

Figure 4 shows schematically the experimental device for measuring the switching times (GIEsSELMANN, ZUGENMAIER). The measured transmission curves were transformed into relative transmission values, and from these curves, plots versus time, the on- and off-switching times were determined. Because of the very slow relaxation during the last $10 \%$ of the relative transmission, the switching times were determined for a relative change of the transmission from $0 \%$ to $90 \%$ and $100 \%$ to $10 \%$, respectively.

The advantage of this method for the determination of the switching times, compared to the high frequency AC-field method introduced by PELzL et al. (1987), is that the process of switching can be directly followed up on the screen.

\section{Experimental results}

The switching times for the different compounds shown in Figure 5 were measured for the nematic as well as the smectic $C$ phase as a function of the applied external field.<smiles>CCCCCCc1cnc(-c2ccc(OC(=O)O)cc2)nc1</smiles>

$\mathrm{C} 2$<smiles>OCCCCCc1cnc(-c2ccc(O)cc2)nc1</smiles>

C3

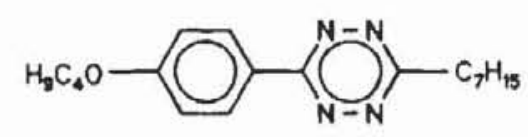

C4

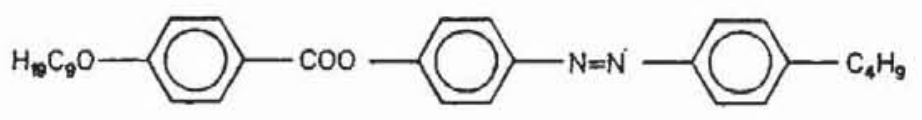

C5<smiles></smiles>

Fig. 5. Compounds studied and their abbreviations, as used in this paper 
Table 1

Phase transition temperatures and threshold voltage $U_{0}$ for the compounds studied

\begin{tabular}{|c|c|c|c|c|}
\hline Compound; transition temperatures & Ref. & Phase & $T /{ }^{\circ} \mathrm{C}$ & $U_{0} / \mathrm{V}$ \\
\hline $\begin{array}{l}C 1 \\
K 29 S_{\mathrm{c}} 54 S_{\mathrm{A}} 61.3 N 67.7 I\end{array}$ & $\left({ }^{*}\right)$ & $\begin{array}{l}N \\
S_{\mathrm{c}} \\
S_{\mathrm{c}}\end{array}$ & $\begin{array}{l}64 \\
50 \\
40\end{array}$ & $\begin{array}{r}8.8 \\
17.7 \\
19.4\end{array}$ \\
\hline $\begin{array}{l}C 2 \\
K 27 S_{\mathrm{c}} 47 S_{\mathrm{A}} 58 N 66 I\end{array}$ & $(*)$ & $\begin{array}{l}N \\
S_{\mathrm{c}}\end{array}$ & $\begin{array}{l}62 \\
43\end{array}$ & $\begin{array}{r}6.3 \\
28.0\end{array}$ \\
\hline $\begin{array}{l}C 3 \\
K 47\left(S_{\mathrm{c}} 42.7\right) N 61.7 I\end{array}$ & $(\S)$ & $\begin{array}{l}N \\
N \\
S_{\mathrm{c}}\end{array}$ & $\begin{array}{l}58 \\
48 \\
40.5\end{array}$ & $\begin{array}{r}7.7 \\
13.7 \\
7.0\end{array}$ \\
\hline $\begin{array}{l}C 4 \\
K 84.5 S_{\mathrm{c}} 91.7 N 191.1 I\end{array}$ & $(\dagger)$ & $\begin{array}{l}N \\
S_{\mathrm{c}}\end{array}$ & $\begin{array}{l}185 \\
86.5\end{array}$ & $\begin{array}{r}4.0 \\
15.8\end{array}$ \\
\hline $\begin{array}{l}C 5 \\
K 94\left(S_{\mathrm{c}} 76.8\right) S_{\mathrm{A}} 117.4 N 120.8 I\end{array}$ & $\left(\begin{array}{l}+ \\
+\end{array}\right)$ & $\begin{array}{l}N \\
S_{\mathrm{c}}\end{array}$ & $\begin{array}{r}119 \\
74\end{array}$ & $\begin{array}{r}6.0 \\
15.0\end{array}$ \\
\hline
\end{tabular}

* ZASCHKE.

$\S$ Demus, Krücke, Kuschel, Nothnick, Pelzl, Zaschke.

$\dagger$ ZaschKe, DebaQ, Schubert.

+ Weissflog, Möckel, Kolbe, Kresse, Pelzl, Mohr, Zaschke.

Table 1 shows the phase transition temperatures and the threshold voltage for the studied compounds.

Tables 2-6 represent the switching times of the nematic and the smectic $C$ phase determined for different applied voltages. The thickness of the cells was $2 \mu \mathrm{m}$ in all cases.

Table 2

Switching times for compound $C 1$ for an applied voltage $U$

\begin{tabular}{|c|c|c|c|c|}
\hline Phase & $T /{ }^{\circ} \mathrm{C}$ & $U / \mathrm{V}$ & $\tau_{\text {rise }} / \mathrm{ms}$ & $\tau_{\text {decay }} / \mathrm{ms}$ \\
\hline$N$ & 64 & $\begin{array}{l}21.0 \\
30.6 \\
40.3 \\
50.3\end{array}$ & $\begin{array}{l}1.4 \\
0.57 \\
0.26 \\
0.16\end{array}$ & $\begin{array}{l}4.4 \\
4.6 \\
4.8 \\
5.0\end{array}$ \\
\hline$S_{\mathrm{c}}$ & 50 & $\begin{array}{l}30.3 \\
40.3 \\
50.3 \\
59.4\end{array}$ & $\begin{array}{l}1.36 \\
0.50 \\
0.31 \\
0.21\end{array}$ & $\begin{array}{l}0.12 \\
0.12 \\
0.13 \\
0.14\end{array}$ \\
\hline$S_{\mathrm{c}}$ & 40 & $\begin{array}{l}30.6 \\
40.3 \\
50.3 \\
59.4 \\
71.1 \\
80.6\end{array}$ & $\begin{array}{l}1.59 \\
0.58 \\
0.33 \\
0.23 \\
0.17 \\
0.15\end{array}$ & $\begin{array}{l}0.11 \\
0.12 \\
0.13 \\
0.13 \\
0.14 \\
0.15\end{array}$ \\
\hline
\end{tabular}


Table 3

Switching times for compound $C 2$

\begin{tabular}{lllll}
\hline Phase & $T /{ }^{\circ} \mathrm{C}$ & $U / \mathrm{V}$ & $\tau_{\text {rise }} / \mathrm{ms}$ & $\tau_{\text {decay }} / \mathrm{ms}$ \\
\hline \multirow{4}{*}{$N$} & & 13.0 & 1.4 & 4.0 \\
& & 20.0 & 0.55 & 4.2 \\
& 62 & 24.0 & 0.32 & 4.0 \\
& & 30.0 & 0.20 & 4.1 \\
& & 35.0 & 0.14 & 4.2 \\
$S_{\mathrm{c}}$ & 43 & 39.0 & 0.43 & 0.32 \\
& & 45.0 & 0.27 & 0.20 \\
& & 50.0 & 0.22 & 0.33 \\
& & & & \\
\hline
\end{tabular}

Table 4

Switching times for compound $C 3$

\begin{tabular}{lcrll}
\hline Phase & $T /{ }^{\circ} \mathrm{C}$ & $U / \mathrm{V}$ & $\tau_{\text {rise }} / \mathrm{ms}$ & $\tau_{\text {decay }} / \mathrm{ms}$ \\
\hline & & 20.0 & 0.94 & 3.4 \\
& & 30.3 & 0.35 & 3.4 \\
$N$ & \multirow{3}{*}{58} & 40.3 & 0.19 & 3.4 \\
& & 50.3 & 0.11 & 3.3 \\
& & 61.0 & 0.08 & 2.8 \\
& & 69.7 & 0.06 & 2.2 \\
& & 79.0 & 0.04 & 1.5 \\
& & 30.6 & 2.47 & 1.9 \\
& & 40.6 & 0.56 & 2.0 \\
$N$ & 40.3 & 0.33 & 2.0 \\
& & 61.0 & 0.22 & 2.1 \\
& & 71.1 & 0.16 & 2.1 \\
& & 81.3 & 0.12 & 2.2 \\
$S_{c}$ & 90.3 & 0.09 & 2.2 \\
& & 101.0 & 0.07 & 2.1 \\
& 40.5 & 10.0 & 4.68 & 0.94 \\
& & 15.0 & 1.69 & 1.14 \\
& & 20.0 & 0.81 & 1.14 \\
\hline
\end{tabular}

Tables 2-6 clearly show that the on-switching times decrease with increasing field strength, whereas the off-switching times are nearly constant, that is field-independent, as expected.

It is worth mentioning that the off-switching times in the $S_{\mathrm{c}}$ phase of compounds $C 1$ through $C 4$ are clearly shorter than in the nematic phase, whereas compound $C 5$ shows the opposite behaviour. 
Table 5

Switching times for compound $\mathrm{C} 4$

\begin{tabular}{lccll}
\hline Phase & $T /{ }^{\circ} \mathrm{C}$ & $U / \mathrm{V}$ & $\tau_{\text {rise }} / \mathrm{ms}$ & $\tau_{\text {decay }} / \mathrm{ms}$ \\
\hline \multirow{4}{*}{$N$} & & 19.8 & 0.29 & 1.3 \\
& \multirow{3}{*}{185} & 40.3 & 0.069 & 1.5 \\
& & 59.8 & 0.057 & 1.9 \\
& & 81.3 & 0.042 & 3.7 \\
& & 90.3 & 0.029 & 2.1 \\
& & 40.6 & 0.40 & 0.39 \\
$S_{\mathrm{c}}$ & 50.3 & 0.28 & 0.41 \\
& & 59.8 & 0.20 & 0.37 \\
& & 71.1 & 0.15 & 0.32 \\
& & 79.8 & 0.13 & 0.26 \\
& & 90.5 & 0.11 & 0.24 \\
\hline
\end{tabular}

Table 6

Switching times for compound $\mathrm{C} 5$

\begin{tabular}{lllll}
\hline Phase & $T /{ }^{\circ} \mathrm{C}$ & $U / \mathrm{V}$ & $\tau_{\text {rise }} / \mathrm{ms}$ & $\tau_{\text {decay }} / \mathrm{ms}$ \\
\hline & & 15.0 & 0.25 & 2.0 \\
& & 20.0 & 0.14 & 1.7 \\
$N$ & 25.0 & 0.092 & 2.1 \\
& \multirow{3}{*}{119} & 30.0 & 0.050 & 1.7 \\
& & 35.0 & 0.037 & 1.9 \\
& & 40.0 & 0.030 & 1.8 \\
& & 20.0 & 0.41 & 9.5 \\
$S_{\text {c }}$ & 74 & 30.0 & 0.47 & 11.1 \\
& & 50.0 & 0.12 & 11.9 \\
& & 50.0 & 0.054 & 11.9 \\
\hline
\end{tabular}

The threshold of the Freedericksz transition (2) yields the elastic constant

$$
B=\frac{U_{0}^{2} \Delta \varepsilon \varepsilon_{0} \sin ^{2} \Theta}{\pi^{2}}
$$

in the case of bookshelf geometry, $\mu=0$, and

$$
B=\frac{\Theta_{0}^{2} \Delta \varepsilon \varepsilon \sin ^{2} \Theta \cos ^{2} \Theta}{(4.6)^{2}}
$$

in the case of layer-tilted geometry with $\mu=\Theta, U_{0}$ being the threshold voltage $U_{0}=E_{\mathrm{c}} D$.

A qualitative confirmation of equation (9) was found by plotting $\tau_{\text {rise }}$ versus $\left(U^{2}-U_{0}^{2}\right)^{-1}$, which resulted in a very good linear dependence.

Table 7 shows the elastic constants of the $S_{\mathrm{c}}$ phase, together with the elastic splay constant $k_{11}$ of the nematic phase, obtained by MEIER et al.

$$
k_{11}=U_{0}^{2} \frac{\Delta \varepsilon \varepsilon_{0}}{\pi^{2}}
$$


Table 7

Elastic splay constant $k_{11}$ of the nematic phase, elastic constant $B$ and reduced elastic constant $B_{0}$ of the smectic $C$ phase. $U_{0}$ being the threshold voltage, $\theta$ the tilt angle and $\Delta \varepsilon$ the dielectric anistropy. Values in brackets were calculated for layer tilted geometry, using equation (11)

\begin{tabular}{|c|c|c|c|c|c|c|c|c|}
\hline Com. & Phase & $\begin{array}{l}T \\
{ }^{\circ} \mathrm{C}\end{array}$ & $\begin{array}{l}U_{0} \\
\mathrm{~V}\end{array}$ & $\begin{array}{l}\theta \\
\rho^{\circ}\end{array}$ & $\Delta \varepsilon$ & $\begin{array}{l}k_{11} \\
10^{-12} \mathrm{~N}\end{array}$ & $\begin{array}{l}B \\
10^{-12} \mathrm{~N}\end{array}$ & $\begin{array}{l}B_{0} \\
10^{-12} \mathrm{~N}\end{array}$ \\
\hline$C 1$ & $\begin{array}{l}N \\
S_{\mathrm{c}} \\
S_{\mathrm{c}}\end{array}$ & $\begin{array}{l}64 \\
50 \\
40\end{array}$ & $\begin{array}{r}8.8 \\
17.7 \\
19.4\end{array}$ & $\begin{array}{l}12.5 \\
20\end{array}$ & $\begin{array}{l}0.53 \\
0.46 \\
0.46\end{array}$ & 37 & $\begin{array}{c}6.1(2.7) \\
18(7.4)\end{array}$ & $\begin{array}{l}129(58) \\
153(63)\end{array}$ \\
\hline$C 2$ & $\begin{array}{l}N \\
S_{\mathrm{c}}\end{array}$ & $\begin{array}{l}62 \\
43\end{array}$ & $\begin{array}{r}6.3 \\
28.0\end{array}$ & 20 & $\begin{array}{l}0.5 \\
0.46\end{array}$ & 18 & $38(16)$ & 323 (134) \\
\hline$C 3$ & $\begin{array}{l}N \\
N \\
S_{\mathrm{c}}\end{array}$ & $\begin{array}{l}58 \\
48 \\
40.5\end{array}$ & $\begin{array}{r}7.7 \\
13.7 \\
7.0\end{array}$ & 25 & $\begin{array}{l}0.5 \\
0.5 \\
0.4\end{array}$ & $\begin{array}{l}27 \\
84\end{array}$ & $3.1(1.2)$ & $18(6.7)$ \\
\hline$C 4$ & $\begin{array}{l}N \\
S_{\mathrm{c}}\end{array}$ & $\begin{array}{l}185 \\
86.5\end{array}$ & $\begin{array}{r}4.0 \\
15.8\end{array}$ & 15 & $\begin{array}{l}0.45 \\
0.27\end{array}$ & 6.5 & $4.1(1.8)$ & $61(27)$ \\
\hline$C 5$ & $\begin{array}{l}N \\
S_{\mathrm{c}}\end{array}$ & $\begin{array}{r}119 \\
74\end{array}$ & $\begin{array}{r}6.0 \\
15.0\end{array}$ & 15 & $\begin{array}{l}3.0 \\
2.4\end{array}$ & 97 & $32(14)$ & $478(208)$ \\
\hline
\end{tabular}

For all compounds, the elastic splay constant $k_{11}$ of the nematic phase is larger than the elastic constant $B$ of the smectic $C$ phase, with the exception of $C 2$. Since $B$ is directly proportional to $\sin ^{2} \theta$, it seems reasonable to compare $k_{11}$ with a reduced elastic constant $B_{0}=B / \sin ^{2} \theta$. Table 7 shows that $B_{0}$ is larger than $k_{11}$ for all compounds studied, with the exception of $C 3$.

Table 8

Rotational viscosity $\lambda$ for the nematic and smectic $C$ phase and reduced rotational viscosity $\lambda_{0}$ for the smectic $C$ phase. Values in brackets were calculated for layer tilted geometry

\begin{tabular}{|c|c|c|c|c|c|}
\hline Comp. & Phase & $T /{ }^{\circ} \mathrm{C}$ & $\tau_{\text {decay }} / \mathrm{ms}$ & $\lambda / \mathrm{mPa} \mathrm{s}$ & $\lambda_{0} / \mathrm{mPa} \mathrm{s}$ \\
\hline$C 1$ & $\begin{array}{l}N \\
S_{\mathrm{c}} \\
S_{\mathrm{c}}\end{array}$ & $\begin{array}{l}64 \\
50 \\
40\end{array}$ & $\begin{array}{l}4.7 \\
013 \\
0.13\end{array}$ & $\begin{array}{l}429 \\
2(0.9) \\
5.8(2.4)\end{array}$ & $\begin{array}{l}42(19) \\
49(21)\end{array}$ \\
\hline$C 2$ & $\begin{array}{l}N \\
S_{\mathrm{c}}\end{array}$ & $\begin{array}{l}62 \\
43\end{array}$ & $\begin{array}{l}4.1 \\
0.26\end{array}$ & $\begin{array}{r}182 \\
25(11)\end{array}$ & $210(90)$ \\
\hline$C 3$ & $\begin{array}{l}N \\
N \\
S_{\mathrm{c}}\end{array}$ & $\begin{array}{l}58 \\
48 \\
40.5\end{array}$ & $\begin{array}{l}2.9 \\
2.1 \\
1.1\end{array}$ & $\begin{array}{l}190 \\
430 \\
8.4(3.3)\end{array}$ & $47(19)$ \\
\hline$C 4$ & $\begin{array}{l}N \\
S_{\mathrm{c}}\end{array}$ & $\begin{array}{l}185 \\
86.5\end{array}$ & $\begin{array}{l}2.1 \\
0.33\end{array}$ & $\begin{array}{l}34 \\
3.4(1.5)\end{array}$ & $51(22)$ \\
\hline C5 & $\begin{array}{l}N \\
S_{\mathrm{c}}\end{array}$ & $\begin{array}{r}119 \\
74\end{array}$ & $\begin{array}{r}1.9 \\
11.1\end{array}$ & $\begin{array}{l}447 \\
876(383)\end{array}$ & 13083 \\
\hline
\end{tabular}


From equation (5) the rotational viscosity can be determined to

$$
\lambda=\frac{\overline{\tau_{\text {decay }}} B \pi^{2}}{D^{2}}
$$

using the average off-switching time.

Table 8 depicts the rotational viscosity as well as the reduced rotational viscosity $\lambda_{0}=\lambda / \sin ^{2} \theta$ as compared to the nematic phase.

The rotational viscosity $\lambda$ of the nematic phase for all compounds is clearly larger than for the smectic $C$ phase, with the possible exception of $C 5$, depending on the layer geometry. Comparing the reduced rotational viscosities $\lambda_{0}$, it is found that for compounds $C 1$ and $C 3$ the reduced rotational viscosity in the nematic phase is still larger than in the smectic $C$ phase, whereas compounds $C 4$ and $C 5$ show the opposite behaviour. This might be explained by the temperature dependence of the rotational viscosity: compounds $C 4$ and $C 5$ exhibit a wide nematic temperature range ahead of the smectic $C$ phase $\left(100^{\circ} \mathrm{C}\right.$ and $\left.43^{\circ} \mathrm{C}\right)$, whereas compounds $C 1$ and $C 3$ show only a small temperature range before the smectic $C$ phase is reached (less than $20^{\circ} \mathrm{C}$ ). Compound $C 2$ will be discussed in more detail below.

\section{Discussion}

Our result for $C 4$ compare very well with measurements on the same compound (listed as C6 by Pelzl et al. 1987), although different methods of investigation were employed. Switching times, elastic constant and rotational viscosity are almost the same, if one takes into account the difference in the thickness of the cells and the fact that a DC-field was used in our study instead of an AC-field by PELzL et al. (1987) for which an additional factor 2 arises, since the effective voltage is $U_{\text {eff }}=U / \sqrt{2}$. Slight differences can be accounted for by slightly different temperatures for both measurements. The splay elastic constant $k_{11}$ of the nematic phase can not be compared, because of totally different measuring temperatures.

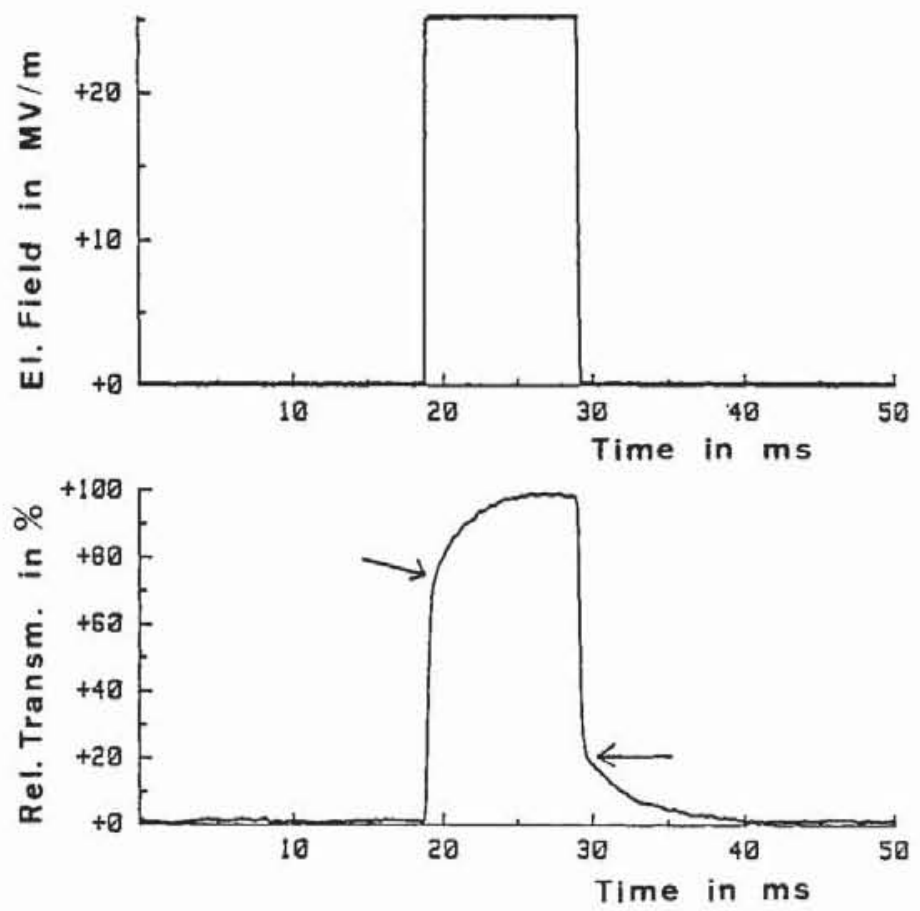

Fig. 6. (a) applied electric field strength (top) and (b) relative transmission curve for compound $C 2$ (bottom) 
Similar compounds were investigated as $C 1$ (compared to $C 1$ in PeLzL et al. 1987) and C5 (C9 in PELZL et al. 1987) and yield comparable results with the corrections for the thickness of the cells and the effective voltage, as well as differences in temperature.

The excellent agreement of the determined switching times, elastic constant and rotational viscosity as compared to the results by PELZL et al. (1987), for various thicknesses of cells and different measuring methods can be regarded as a proof of the theoretical interpretation of the Freedericksz transition of planar oriented smectic $C$ phases with positive dielectric anisotropy given by PELzL et al. (1987) and suggests that the measurement of switching times represents a simple method to estimate those constants, provided that the tilt angle and the dielectric anistropy are known. It should be noted that the elastic constant and the rotational viscosity calculated for bookshelf geometry and layer tilted geometry are clearly different so that one has to take into account the geometry of the smectic layers in the cell, interpretating these constants.

A plot of the complete on- and off-switching process during the application of a pulse voltage seems to indicate a switching process with two different mechanisms for compounds $C 1$ through $C 3$, as can be seen for $C 2$ in Figure $6 \mathrm{~b}$ (see arrows). The relative transmission curve for $C 2$ as representative example is depicted with pulse width $10 \mathrm{~ms}$, pulse repetition rate $1 \mathrm{cps}$ and applied voltage of $50 \mathrm{~V}$.

Using the electrooptical method presented by Giesselmann and ZugenMaier, we determined the mean director motion during the switching process in the laboratory coordinate system fixed to the substrates for compound $C 2$ at $43{ }^{\circ} \mathrm{C}$. With the described experimental setup, only using a triangular driving voltage of $50 \mathrm{~V}$ and $5 \mathrm{~Hz}$, the "in-plane angle" $\varphi_{\mathrm{s}}$ and the "off-plane angle" $\vartheta_{\mathrm{s}}$ can be determined by two transmission measurements at a sample rotation angle $\varphi_{0}$ and at a sample rotation angle $\varphi_{0}+45^{\circ}$. A plot of $\vartheta$ as a function of $\varphi_{\mathrm{s}}$ then represents a projection of the director trajectory onto the smectic layer plane (cf. Fig. 3).

The left side of the diagram in Figure 7 depicts the director motion determined by the transmission curve of a single bright appearing domain, whereas the right part of the diagram shows the director motion of a single dark appearing domain of the sample in the cell,

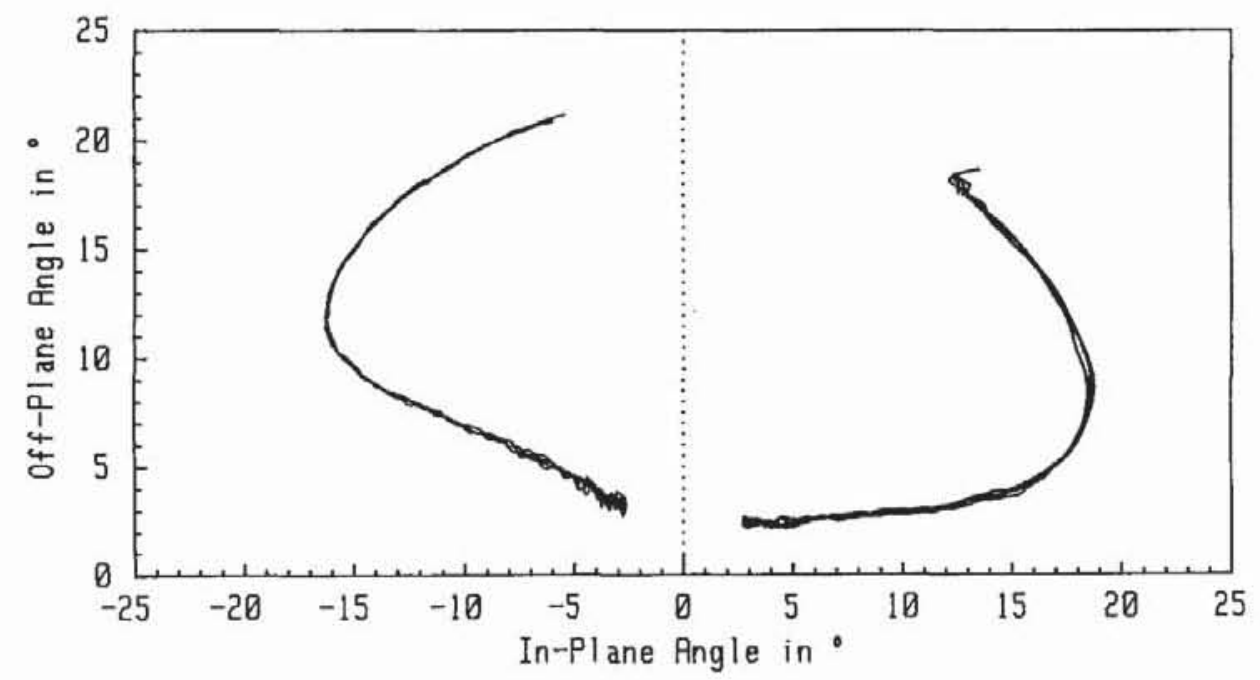

Fig. 7. Projection of the director trajectory on the smectic layer plane during a field induced reorientation 


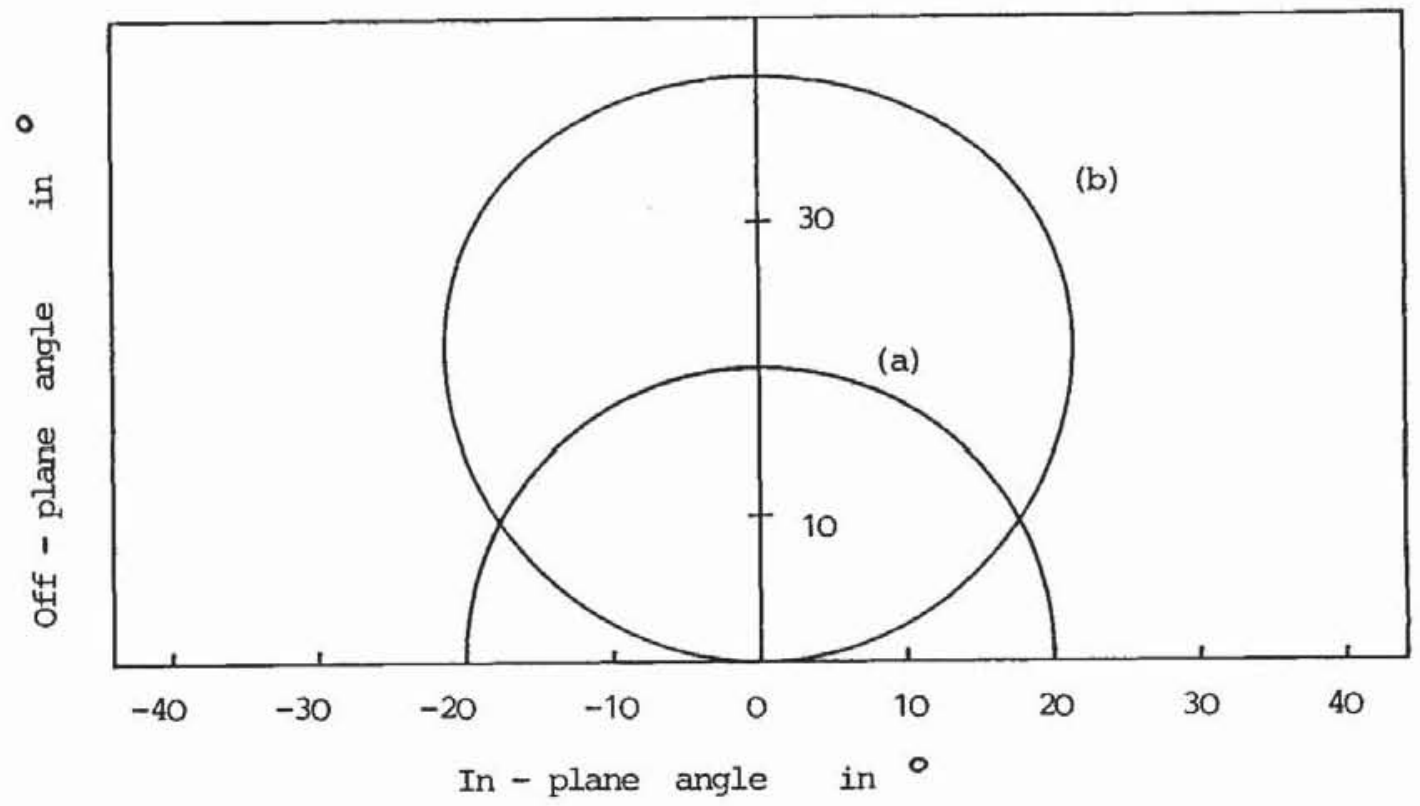

Fig. 8. Projection of the director trajectory onto the smectic layer plane, calculated for (a) bookshelf geometry and (b) layer tilted geometry with $\mu=20^{\circ}$.

clearly showing that the director is moving around the tilt-cone in different directions for the two different domain types, as was suggested by PelzL et al. (1987).

Figure 8 depicts a calculated director trajectory for a layer tilted geometry with $\mu=20^{\circ}$ (curve (b)), and bookshelf geometry (curve (a)). The upper part of the measured director trajectory (Fig. 7) seems to suggest an orientation of the smectic layers in bookshelf- or slighty tilted geometry (cf. Fig. 8 (a)), since the orientation with $\mu \approx 0$ shows a director trajectory with an off-plane angle going up to $20^{\circ}$, whereas the orientation with $\mu=\theta$ should show off-plane angles going up to $40^{\circ}$. At low electric field strength (low off-plane angles) there is a significant deviation of the measured director trajectory from Figure 8 (a) and the projection of the mean director motion onto the smectic layer plane either suggests an orientation of the smectic layers in the layer tilted geometry (cf. Fig. 8 (b)) or a nonuniform director distribution.

\section{References}

Demus, D., Krücke, B., Kuschel, F., Nothnick, H. U., Pelzl, G., Zaschke, H.: Mol. Cryst. Liq. Cryst. (Lett.) 56 (1979) 115

Giesselmann, F., Zugenmaier, P.: Liq. Cryst. 8 (1990) 361

Meier, G., Sackmann, E., Grabmaier, J. G.: Applications of Liquid Crystals, Berlin 1975, p. 13

Meirovich, E., Luz, Z., Alexander, S.: Phys Rev. A 15 (1977) 408

Pelzl, G., Kolbe, P., Preukschas, U., Diele, S., Demus, D.: Mol. Cryst. Liq. Cryst. 53 (1979) 167

Pelzl, G., Schiller, P., Demus, D.: Liq. Cryst. 2 (1987) 131

Pelzl, G., Schubert, H., ZaschKe, H., Demus, D.: Kristall Technik 14 (1979) 817

Rapini, A.: J. Phys. (Paris) 33 (1972) 237

Weissflog, W., Möckel, P., Kolbe, A., Kresse, H., Pelzl, G., Mohr, K., Zaschke, H.: Jour. Prakt. Chem. 326 (1984) 457 
Cryst. Res. Technol. 27 (1992) 5

ZaSChKe, H.: Jour. Prakt. Chem. 317 (1975) 617

Zaschke, H., DebaQ, J., Schubert, H.: Z. Chem. 15 (1975) 100

(Received, accepted January 3, 1992)

Authors' address:

I. Dierking, Dipl. Chem. F. Giesselmann,

Prof. Dr. P. ZugenmaIer, Institut für Physikalische Chemie der TU Clausthal

Arnold-Sommerfeld-Str. 4

W-3392 Clausthal-Zellerfeld, Germany

Dr. G. Pelzl, Dr. P. Schiller

Fachbereich Chemie, Institut für Physikalische Chemie,

Martin-Luther Universität, Mühlpforte 1

O-4020 Halle (Saale), Germany 